\title{
4
}

\section{IFIP Working Group 3.4: training and education of information technology professionals}

\author{
Peter Juliff \\ Chair of IFIP Working Group 3.4 \\ Deakin University \\ Melbourne, Australia
}

\begin{abstract}
IFIP Working Group 3.4 is concerned with the training and education of IT professionals and advanced end-users. It draws together academics and practitioners from across the world to discuss issues relating to the on-going professional education required by IT practitioners and the implications which this has on the curriculum of educational institutions. The working group is also interested in the activities of professional computing bodies concerning the accreditation of their members and the certification of the currency of their knowledge. This paper describes the aims and activities of Working Group 3.4 and outlines the themes to be developed by its Professional Groups during the world conference.
\end{abstract}

Main conference themes: accreditation, informatics as study topic, information technology

Educational areas: professional development, vocational education

Study topics:

Secondary keywords: curriculum policies, management 


\section{INTRODUCTION}

Under the umbrella of IFIP Technical Committee 3 (TC 3) concerned with information technology education Working Group 3.4 (WG 3.4) is primarily focused on the educational needs of practising Information Technology (IT) professionals and advanced end-users. While not involved with the individual course syllabuses of educational institutions, the WG 3.4 is concerned with the overall outcome of IT education in as much as it affects the competencies of practitioners and end-users, and their need for further on-going professional development.

\section{The aims of Working Group 3.4}

As set out in its prospectus the aims of the Working Group are:

- To promote effective education and training of professionals and advanced end-users in the field of information technology.

- To examine current curricula and investigate the need for changing them to adapt to the fast changes of the technology.

- To make examples of good practice in basic and continuing education more widely known.

- To study, examine and provide guidance on training and education methodologies and organization of study.

- To consider developments in educational technology (e.g. computer mediated education, multimedia and distance learning), evaluate their application and provide guidance and recommendations considering their integration into training systems.

- To examine qualifications, certification and career development paths, compare them, provide recommendations for changing them and for granting them mutual international recognition.

The scope of these operations is seen to embrace education at secondary, postsecondary and vocationally oriented institutions for those who will be regarded as IT professionals and end-users who are capable of contributing significantly to the development of IT systems.

\section{Membership and activities}

Membership of the Working Group consists predominantly, but not exclusively, of academics from countries in Europe, Africa and the Middle-East, and the Asia-Pacific region. Working conferences are held annually in the countries of the constituent members. 
Themes addressed by recent working conferences have included:

- 1989: Methodologies of training data processing professionals and advanced end-users. Helsinki, Finland.

- 1991: Training-from computer aided design to computer integrated enterprise. Alesund, Norway.

- 1992: Professional development of information technology professions Singapore [1].

- 1993: Computer mediated education of information technology professionals and advanced end-users. Soest, Germany [2].

- 1993: Software engineering education. Hong Kong.

- 1994: Information technology in educational management. Jerusalem, Israel [3].

- 1994: Software quality and productivity. Hong Kong [4].

and a forthcoming conference will address:

- 1996: Information technology in management education. Melbourne, Australia.

Working conferences are normally restricted to the participants presenting papers and to selected invitees who are able to add to the content of the discussion.

\section{PROFESSIONAL GROUPS AT WCCE95}

The following themes are addressed in WCCE95 as representing major issues of concern to WG 3.4:

Information Officers: a new function in organisations; their role, responsibility, education and updating.

There is a growing acceptance of the importance of information as the most valuable resource possessed by most organisations. The management of this resource, as opposed to its mere husbandry, is a key factor in providing its parent organisation with a competitive edge in the marketplace.

The custody of management information systems has been often left in the hands of the technologists who manage the physical resources associated with implementation of those systems. Professional bodies such as societies of accountants are staking a claim to be seen as the natural managers of an organization's information in the same sense as they are seen as managers of its money. One of the problems inherent in such a claim is that accounting education does not equip its graduates with sufficient breadth or depth of knowledge in information systems to be able to fill that role. 
There is a need for the recognition of the role of a Chief Information Officer (CIO) who is a member of the management team of an organization. This CIO would need to be a hybrid graduate, educated in both management and information technology. This, in turn, will have an impact on tertiary educators in the design of new courses to produce this new breed of graduate.

\section{Professional updating of IT professionals, educators and trainers.}

Information technology in its many facets is one of the fastest changing areas of human endeavour. More than most, if not all, other professional IT practitioners must keep abreast of advances in the various components of their craft. These include hardware, communications technology, software applications and development methodologies. The half-life of most useful knowledge is measured in a handful of years.

There is a need for IT graduates to update their knowledge continually by means of professional development activities. Members of the public relying on the level of competence of such professionals have a right to know whether their knowledge has been kept up to date. IT professional societies have been concerned with this issue for some years. There is a variety of schemes by which a practitioner may pursue a continuing program of professional development and obtain an updated 'practising certificate'.

The same issues confronting practitioners apply also to those responsible for their education and training. Educational institutions are not traditionally geared to continual changes in curricula and a need for continual replacement and enhancement of resources. There is a need for those in charge of educational budgets to realize that the maintenance of an up to date IT program will need to be funded on a similar basis as a laboratory based discipline such as engineering. This falls particularly hard on business schools which teach information systems in an environment long been funded on the assumption that chalk and blackboards are the leading edge of educational technology.

Research in information technology in education management: state of the art and future directions

The nature of the work done by education administrators and the mode by which it is accomplished are changing as a result of a wider penetration of computer based systems into education management. This is becoming as true for primary and secondary education as it is for colleges and universities.

School databases are being developed encompassing data on students, teachers, employees, classrooms, grade levels, courses, student achievements and behaviour, school space, curriculum, finance, inventory, transportation and a host of other aspects of daily education administration. Education and training in the use of these tools however often lags behind the development of 
the systems themselves. Managers and staff are often unaware of the potential of such applications and therefore miss the opportunity to contribute to their design and implementation.

There is much to be gained from the exchange of ideas and experience in the use of IT in typical administrative areas. These may include specific applications such as processing students' grades and other personal data for generating reports for teachers, principals and counsellors on the one hand to the management and scheduling of educational resources on the other. They may also explore the potential of applications copied from the realms of business administration such as decision support systems and executive information systems.

\section{CONCLUSION}

The work of IFIP WG 3.4 is essentially to provide an opportunity for its members and associates to share their experience in IT professional education and to suggest policies which may be followed by those countries with a lesser body of such experience. By sponsoring a variety of working conferences on related subjects in the countries of its constituents it provides a forum for the advancement of the aims of IFIP in the dissemination of knowledge and best practice in the information technology profession.

\section{REFERENCES}

1. Barta, B.Z., Goh, A. and Lim, L. (Eds.) (1992) Professional Development of Information Technology Professionals. North-Holland Elsevier.

2. Barta, B.Z., Eccleston, J. and Hambusch, R. (Eds.) (1993) Computer Mediated Education of Information Technology Professionals and Advanced End-Users. North-Holland Elsevier.

3. Barta, B.Z., Telem, M. and Gev Y. (Eds.) (1995) Information Technology in Educational Management. Chapman and Hall.

4. Lee, M., Barta, B. Z. and Juliff, P. (Eds.) (1995) Software Quality and Productivity - Theory, practice, education and training. Chapman and Hall. 